\title{
Marginal learning-set formation by the crow (Corvus brachyrhynchos)
}

\author{
MAXWELL W. HUNTER III \\ Westfield State College, Westfield, Massachusetts 01085 \\ and \\ ALAN C. KAMIL \\ University of Massachusetts, Amherst, Massachusetts 01002
}

\begin{abstract}
Each of three hand raised crows received 300 learning set problems in a modified WGTA using three-dimensional stimuli. Consistent within-problem learning was obtained but learning set formation was minimal. An analysis of hypothesis behavior (Levine, 1959) revealed a strong tendency towards position and stimulus preferences. These results raise the possibility of large species differences in learning set formation within the family Corvidae.
\end{abstract}

We have previously reported successful object-discrimination learning set (ODLS) acquisition in two avian species, a sturnid, the Greater Hill Myna (Gracula religiosa; Kamil \& Hunter, 1970) and a corvid, the bluejay (Cyanocitta cristata; Hunter \& Kamil, 1971). In the current experiment, similar ODLS procedures were administered to another corvid, the crow (Corvus brachyrhynchos). The crow seemed a logical choice for further across-species investigation because of its close taxonomic relationship to the bluejay, because of its widespread reputation for "intelligence," and because of its good performance in other learning situations (Powell, 1974).

\section{METHOD}

\section{Subjects}

The subjects were three crows (Corvus brachyrhynchos) captured in the Amherst, Massachusetts area at approximately 2 weeks of age and hand raised in the laboratory. Each nestling was handled daily in conjunction with feeding and maintained in a communal nest until it was able to perch reliably. At this point, each crow was housed in an individual cage. After rearing, the subjects were maintained on a free-feeding schedule of food and water for 2-1/2 months prior to the experiment. At the outset of the experiment, the subjects were approximately 3-1/2-4 months old.

\section{Apparatus}

The apparatus was a modified Wisconsin General Test Apparatus (WGTA) larger than that employed by Kamil and Hunter (1970). The bird chamber was made of Masonite, $30.5 \times 30.5 \times 45.7 \mathrm{~cm}$ high, with a wooden perch located at one end. A smaller wooden enclosure was attached to the animal chamber on the end nearest the perch. The interior floor of this

This report is based on part of a MS thesis by the first author submitted to the Graduate School, University of Massachusetts. The research was supported in part by Training Grant MH-11823 from the National Institutes of Health and in part by NSF Grant GB-30501. Reprints may be obtained from Maxwell W. Hunter III, Department of Psychology, Westfield State College, Westfield, Massachusetts 01085. enclosure contained two shallow foodwells, $5 \mathrm{~cm}$ apart. The birds had access to the foodwell area through small rectangular ports in front of the foodwells. A Masonite guillotine door separated the foodwell area from the animal chamber during intertrial intervals, and a hinged door constructed of perforated circuit board separated the experimenter from the foodwell enclosure during a trial. The interior portions of the apparatus were painted with nontoxic grey paint. During experimental sessions, the animal chamber was inserted into an accoustically tiled cubicle inside which masking white noise was generated.

The stimuli were three-dimensional "junk" objects (toys, wooden forms, etc.) varying in many dimensions. Reinforcement consisted of a small piece of raw liver or kidney.

\section{Procedure}

The experiment was conducted in three stages: habituation, shaping, and ODLS acquisition. During habituation, each crow was food deprived for $19-20 \mathrm{~h}$ per day, which resulted in a $15 \%$ drop in body weight. At the same time, each crow was given daily 20-min adaptation sessions. Each crow was removed from its home cage, placed in the apparatus, allowed to eat 20 reinforcements, 10 from each foodwell, and returned to its home cage. Each crow received three such adaptation sessions.

The next stage consisted of shaping by successive approximation the response of displacing a stimulus object. Two unpainted wooden blocks served as stimuli. A shaping session consisted of 25 trials with reinforcement available in both foodwells. Gradually the degree to which the objects covered the foodwells was increased and, after three shaping sessions, each crow was retrieving reinforcement from completely covered foodwells.

After shaping was completed, 125 ODLS acquisition sessions were given. In order to facilitate intraproblem learning in the ODLS paradigm, Harlow (1959) suggested that initial problems should be relatively long and, as acquisition continues, problem length should be gradually reduced. This suggestion was followed in the myna and bluejay experiments and was included in the current experiment as follows: Problems 1-15 consisted of 25 trials, Problems 16-103 of 15 trials, and Problems 104-300 of 10 trials each.

The position of the correct object was randomized from trial to trial by employing all possible sequences over Trials 1-3, and sequences suggested by Fellows (1967) were employed for the remaining trials. Daily sessions consisted of 25 or 30 trials, depending on the number of trials per problem, and 


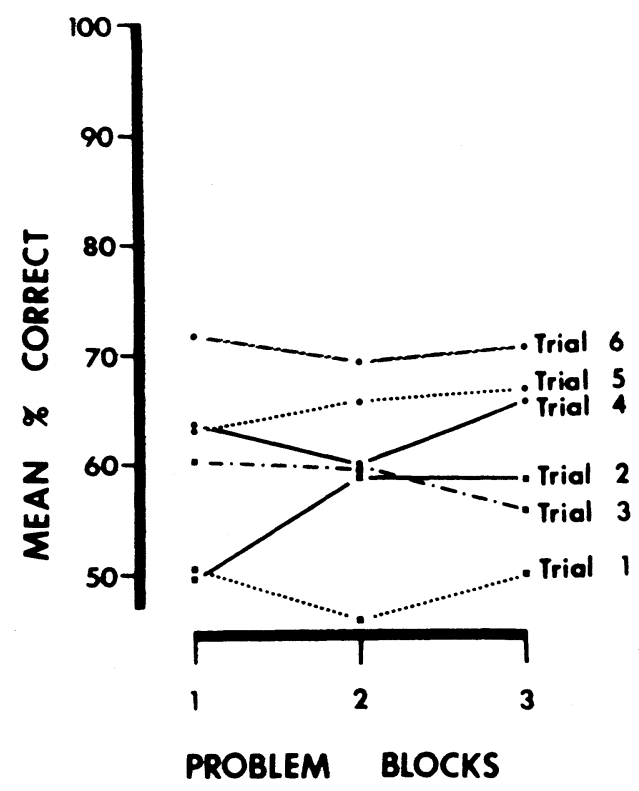

Figure 1. Mean percentage correct on Trials 2-6 for each 100 -problem block of the experiment.

noncorrection procedures were used throughout the experiment. One hundred objects were employed in Problems 1-200, using the random re-pairing procedure described in detail by Kamil and Hunter (1970), and 180 objects were employed in Problems 201-300.

\section{RESULTS}

The ODLS acquisition data are shown in Figure 1. While performance improved from trial to trial within problems, there was very little improvement in performance across problem blocks. In other words, although the crows were able to solve individual object discrimination problems, they showed minimal ODLS acquisition. These performance levels are considerably lower than those previously obtained with either bluejays (Hunter \& Kamil, 1971) or myna birds (Kamil $\&$ Hunter, 1970).
In an attempt to examine the performance of the crows more closely, Levine's $(1959,1965)$ mathematical model of hypothesis behavior during ODLS was applied to these data. The results of this analysis, with the results of similar analyses on the ODLS behavior of bluejays and myna birds, are shown in Table 1. This analysis estimates the probability of each of eight different consistent patterns of responding during Trials 1-3 of each problem. It also yields a statistic called the PVE, an estimate of the extent to which the behavior of the subjects was consistent with the model. Inspection of Table 1 reveals three things about the behavior of the crows: (1) the relatively high PVE value, quite comparable to those obtained with bluejays and mynas as well as with primates (Levine, 1965), indicates that the crows behavior was consistent with the model, showing systematic patterns of choice over Trials 1-3. (2) The probability of the correct strategy, win-stay, lose-shift, object, was much lower for the crow than for either bluejays or mynas, as one would expect from their lower percentage correct. (3) The relatively high estimates for stimulus and position preference suggests that these preferential tendencies, which are much less common in bluejays and myna birds, may have interfered with ODLS acquisition.

\section{DISCUSSION}

These results raise the possibility of large differences in ODLS ability within the family Corvidae. However, it is always difficult to interpret negative results of this sort. On the other hand, it is possible that some aspect of our procedure adversely affected the crows. For example, the crows seemed to become quite emotional about being handled as the experiment progressed. But bluejays and myna birds also display emotional behavior when being handled. Also, the crows sometimes seemed to display some aversion toward novel stimulus objects, indicated by a hesitant approach to newly introduced objects and a quick backward movement after the choice response had been made. Either of these factors, or some other factor, could have artificially suppressed the performance of the crows.

On the other hand, certain aspects of these data suggest that the failure of these crows to acquire ODLS may be an accurate

Table 1

Hypothesis Estimates for Crows, Bluejays (from Hunter \& Kamil, 1971) and Myna Birds (from Kamil \& Hunter, 1970)

\begin{tabular}{|c|c|c|c|c|c|c|c|c|c|}
\hline \multirow[b]{2}{*}{$\begin{array}{c}\text { Group } \\
\text { (Problems) }\end{array}$} & \multicolumn{9}{|c|}{ Hypotheses } \\
\hline & $\begin{array}{c}\text { Position } \\
\text { Prefe- } \\
\text { rence }\end{array}$ & $\begin{array}{c}\text { Position } \\
\text { Alter- } \\
\text { nation }\end{array}$ & $\begin{array}{l}\text { Win-Stay } \\
\text { Lose-Shift } \\
\text { (Position) }\end{array}$ & $\begin{array}{c}\text { Stimulus } \\
\text { Prefe- } \\
\text { rence }\end{array}$ & $\begin{array}{c}\text { Stimulus } \\
\text { Alter- } \\
\text { nation }\end{array}$ & $\begin{array}{l}\text { Third- } \\
\text { Trial } \\
\text { Learning }\end{array}$ & $\begin{array}{c}\text {-Win-Stay } \\
\text { Lose-Shift } \\
\text { (Object) }\end{array}$ & $\begin{array}{l}\text { Random } \\
\text { Respond- } \\
\text { ing }\end{array}$ & PVE \\
\hline $\begin{array}{l}\text { Crow } \\
\qquad(1-300)\end{array}$ & .263 & .036 & .076 & .228 & .034 & .102 & .158 & .220 & .76 \\
\hline $\begin{array}{l}\text { Bluejay } \\
\qquad(1-233)\end{array}$ & .012 & .024 & .065 & .139 & .022 & .228 & .249 & .268 & .71 \\
\hline $\begin{array}{l}\text { Bluejay } \\
(234-466)\end{array}$ & -.003 & .033 & .115 & .100 & .087 & .175 & .484 & .084 & .80 \\
\hline $\begin{array}{l}\text { Bluejay } \\
(467-700)\end{array}$ & .037 & .040 & .022 & .079 & .081 & .128 & .543 & .084 & .85 \\
\hline $\begin{array}{l}\text { Myna } \\
(1140-1300)\end{array}$ & .049 & -.007 & .143 & .018 & .074 & .155 & .412 & .176 & .78 \\
\hline
\end{tabular}


measure of their potential, at least in WGTA type situations which are adequate to produce ODLS formation in bluejays and mynas. The crows seemed well motivated, consistently responding on all trials during a session and consuming all available reinforcements. They did solve individual problems, and the results of the hypothesis analysis shows that they were not responding randomly, but systematically.

These results should be extended through further research. If they represent an accurate assessment of the ability of crows to form a visual learning set, then large differences in ODLS performance exist within a single family. This would suggest that comparative studies of learning might profitably investigate learning in closely related species. Such results would also be counter to Gossette's (1974) taxonomic distance hypothesis, which holds that closely related species, such as members of the same family, should show more similar learning performances than distantly related species. At the present, the ODLS behavior of one corvid, the bluejay, appears to be more similar to that of a sturnid, the myna, than to another corvid, the crow. tasks. Psychological Bulletin, 1967, 67, 87-92.

Gossette, R. L. Note on methodology in comparative behavioral analysis: systematic variation vs. control by equation. Perceptual and Motor Skills, 1974, 39, 155-162.

Harlow, H. F. Learning set and error factor theory. In S. Koch (Ed.), Psychology a study of a science. New York: McGraw Hill, 1959, Vol. 2, Pp. 492-537.

Hunter, M. W., \& Kamil, A. C. Object-discrimination learning set and hypothesis behavior in the northern bluejay (Cyanocitta cristata). Psychonomic Science, 1971, 22, 271-273.

Kamil, A. C., \& Hunter, M. W. Performance on object-discrimination learning set by the Greater Hill Myna (Gracula religiosa). Journal of Comparative and Physiological Psy chology, 1970, 73, 68-73.

Levine, M. A model of hypothesis behavior in discrimination learning-sets. Psy chological Review, 1959, 66, 353-366.

Levine, M. Hypothesis behavior. In A. M. Schrier, H. F. Harlow, and F. Stollnitz (Eds.), In behavior of nonhuman primates: Modern research trend8. Vol. 1, New York: Academic Press, 1965, Pp. 97-127.

Powell, $R$. W. Comparison of differential reinforcement of low rates (DRL) performance in pigeons (Columba livia) and crows (Corvus brachyrhynchos). Journal of Comparative and Physiological Psychology, 1974, 86, 736-746.

\title{
REFERENCES
}

Fellows, B. J. Chance stimulus sequences for discrimination

(Received for publication January 17, 1975.)

Bulletin of the Psychonomic Society

1975, Vol. 5 (5), 375-377

\section{Human evoked brain responses following loud pure tones}

\author{
JAMES K. WALSH and DONALD I. TEPAS \\ Saint Louis University, Saint Louis, Missouri 63103
}

\begin{abstract}
The electroencephalogram (EEG) was recorded at the vertex of three subjects following a 5-min exposure to a $720-\mathrm{Hz}$ pure tone at $110 \mathrm{~dB}$ or $45 \mathrm{~dB}$ SPL. Eight consecutive evoked brain responses (EBRs) to tone bursts were computed from the EEG for a 2-min period following each exposure. The EBRs computed following the 110-dB exposure were initially smaller than those computed following the 45-dB exposure, and this difference became minimal as time after exposure increased. Thus, EBR amplitude data suggest that a temporary threshold shift (TTS) was produced by the 110-dB exposure and that the EBR reflects this change in the listener's sensitivity.
\end{abstract}

A reversable elevation in hearing threshold following exposure to an auditory stimulus is frequently referred to as a temporary threshold shift (TTS). Generally, the difference between a listener's threshold for a standard test signal before and after exposure defines the degree of TTS. Although considerable TTS research is reported in the literature (Miller, 1974; Ward, 1963), little comparable electrophysiological data is evident. Human electrophysiological data are limited to a single brief report of EBR threshold estimations from a single listener following over $24 \mathrm{~h}$ of octave band noise exposure. These data suggest that EBR changes similar to those measured behaviorally are present (Mills,

Requests for reprints should be sent to James $K$. Walsh, Department of Psychology, Saint Louis University, St. Louis, Missouri 63103.
Gengel, Watson, \& Miller, 1970). Since extensive research from numerous laboratories has established the relation of human EBR measures to basic acoustic parameters (Davis \& Zerlin, 1966; McCandless \& Best, 1966; Rapin, Schimmel, Tourk, Krasnegor, \& Pollack, 1966; Tepas, Boxerman, \& Anch, 1972), the observation of Mills et al. (1970) appears reasonable. The present experiment is a further confirmation that human EBR measures are sensitive to noise exposure conditions with known TTS-producing characteristics.

Specifically, we proposed that the amplitudes of EBRs computed immediately following noise exposure would be smaller when exposure conditions approached TTS levels. Using the psychophysical study of Mills and Lilly (1971) as a guide, EBRs computed following a probable TTS-producing exposure were compared with 